GLOBAL JOURNAL OF SOCIAL SCIENCES VOL 16, 2017: $61-75$

COPYRIGHT@ BACHUDO SCIENCE CO. LTD PRINTED IN NIGERIA. ISSN 1596-6216

\title{
THE INTERACTION OF GENDER, GROUP FORMATION, MOBILITY AND AGE ON COWPEA INNOVATION TRANSFER
}

ESTHER WAHAGA

(Received 8 May 2017; Revision Accepted 22 November 2017)

\begin{abstract}
The objective of the study was to explore the relationship between gender, group formation, mobility, age and innovation transfer in cowpea innovation transfer. Data collection was achieved through formal surveys, Focus Group Discussions (FGDs) and observations. A hundred and twenty individual interviews were conducted for the formal survey guided by questionnaire. While 275 community members made up of both male and female farmers, elders, the youth and traders were involved in five Focal Group Discussion Workshops. Results showed that group formation enhanced collective reaction and for that matter technological uptake to others within the group. Results indicated that linkages between men and between women point to a potential for sharing within and between families and villages. Rural urban migration was found to influence the likelihood of innovation adoption. This was a result of their exposure to innovative methods of farming outside the rural farming settings. In terms of age, younger farmers were found to adopt technologies faster though the younger farmers do not have the same years of farming experience. This was because, the young male farmers is prepared to be daring and to take risks, particularly if they control a substantial amount of finance. The high rate of adoption among young farmers also reflects their ability to understand and apply complex technological knowledge. However, the older men found it difficult to change their farming practices because they do not trust new innovations. In adopting an agricultural innovation, the research suggests depends upon a number of factors and these include: age, gender, mobility, being part of a group, availability of inputs and finance, effectiveness of the innovation, the role of traditional norms and values and the level of formal or informal education or what might be referred to as enlightenment. It must be noted that people adopt new agricultural innovations at different times and for different reasons. Group formation was found to positively influence the adoption of new and improved innovations. To promote the adoption of an innovation, age must be critically considered. It has been argued here that young farmers are more ready to adopt innovations than members of other age groups. Older farmers change their practices if there is no alternative to having good quality produce but practice local innovations in the main. In conclusion mobility, gender, group formation and age facilitates innovation adoption and transfer.
\end{abstract}

KEYWORDS: Gender; Group Formation; Mobility; Age; Innovation Transfer; Farmer Field School

\section{INTRODUCTION}

The FFS is one important recent contribution to agricultural development practice (Tripp, Wijeratne \& Piyadasa, 2005), which farmers, National Research Institutions (NRI), the Ministry of Food and Agriculture and some Non-Governmental Organisation (NGOs) have embraced. This paper explores the factors influencing adoption of cowpea innovation in the study villages. It also explores how group formation, mobility and age influence innovation adoption. The decision to focus on these variables emerged during the research in the villages. The paper is also concerned with the impact of innovation and cowpea Integrated Pest management (IPM) Farmer Field School (FFS), and focuses on how these have influenced gender participation in the processes of innovation transfer. It also examines how groups formed during the cowpea IPM FFS have aided farmer-to-farmer innovation transfer. Discussions with FFS group members focused on group activities and processes both during and after the FFS.

Group process in FFS is explored while addressing mobility and innovation adoption. Discussion centres on how the movement of rural farmers from the rural areas to urban areas enhances their adoption of new and improved innovation. It also highlights the category of farmers who were the first to adopt the cowpea IPM techniques under the FFS. In doing so, it provides an explanation as to the importance of rural urban migration in the processes of innovation transfer and adoption. Age cannot be ignored as it also has an impact on innovation adoption and its importance is examined. The respondents were disaggregated into different age groups in order to facilitate this analysis. Here also, the adaptive capacity of women versus men has been discussed. 


\section{The Research Problem and Purpose}

The processes of innovation development, dissemination amongst farm populations, and innovation adoption have been the focus of many studies, since the Second World War when most African countries were gaining independence. At this time national governments of newly independent African countries were struggling with how to extend new techniques and this was reflected in early research work in this area. Rogers' pioneering study underpins the understanding of innovation development, dissemination and adoption.

In recent times, the perception of the processes of innovation, diffusion and adoption, have significantly changed. Scientific research is no longer seen as the only basis of technological innovations, and the direct participation of farmers in formal research processes is viewed as crucial. Farmers, along with frontline agricultural development agencies such as those in the three agricultural development agencies under study here, are all actors who impact on these processes. While Rogers focused on scientific developments to be extended to farmers, the contemporary emphasis has shifted to a focus on working with farmers from the bottom up, and thereby drawing upon their knowledge as a way to modifying their practices.

Ghana provides an excellent case study for examining innovation development, diffusion and adoption. In Ghana, agriculture has always been the largest sector of the economy, contributing about 50 percent to the Gross Domestic Product (GDP) and accounting for about half the country's export earnings. Clare Bishop-Sambrook indicated that the agricultural sector employs more than 80 per cent of Ghana's workforce, and according to the UN, close to 50 per cent of population are now urbanised (Bishop-Sambrook 2005; UN 2008). In addition small-scale farmers produce eighty-five per cent of agricultural products in Ghana.

The research is drawn from fieldwork in northern Ghana. More specifically, data was gathered from communities within relatively easy reach of Tamale, the capital of the northern region. Northern Ghana is the focus because it is known, along with other parts of Ghana, as having been ignored by researchers and successive governments, so that it is a region with very limited access to modern and improved innovations. This absence of attention reinforces the importance of the research into agricultural practices, especially at a time when agriculture in Sub-Saharan Africa has the attention of a wide audience, both within and outside Ghana. Within broader concerns about agricultural production in Sub-Saharan Africa, northern Ghana nevertheless remains a neglected area.

Central to the vitality of cowpea are the impact of pests and diseases and so attempts to develop IPM innovations are at the core of the work of the FFS. The FFS has been enthusiastically adopted in a number of countries that continue to face the challenge of finding processes of knowledge communication and dissemination that can make a significant impact on the agriculture of small and/or poor farmers, and particularly amongst women in farming communities (PEDUNE 2000). In this respect, the communities of northern Ghana are no exception. However, there is very little evidence of the impact of mobility, gender, group formation and age on the adoption and transfer of either FFS or the use of IPM strategies.

The objective of the study was to explore the relationship between gender, group formation, mobility, age and innovation transfer.

\section{Innovation Diffusion and Adoption}

Technological change is the foundation for increased agricultural productivity and development and for that matter technologies that target pest and diseases, varietal traits, nutrient efficiency, water retention/irrigation and post-harvest are important. Many countries have historically pursued agricultural innovation long before now for the expansion and development of the agricultural sector (Kumar et at., 2017). The expansion of agricultural production requires the diffusion and adoption of new scientific and agricultural knowledge for producers to compete on world markets (Prieto, 2013). In Africa, for agriculture to develop, technology transfer and the use of appropriate agricultural inputs are critical for increased agricultural production and for that matter economic advancement (Davidson, 2016). With the right inputs, agro-ecological and socio-cultural environment, agriculture can be transformed (Davidson, 2016). However, when there is a transfer of innovation, from one community to another, the innovation is reworked in harmony with the concepts of local societies, who indigenise its practices (Roncaglia, 2013).

Agricultural advancement can only be possible where researchers and farmers have good communication links among them. Communicating the use of new technology in a social setting is consequently important for agricultural advancement. The process of communicating innovations to change behaviour is referred to as diffusion. To understand how knowledge is shared and what makes innovation transfer possible, Rogers' philosophies on diffusion contributes significantly to this understanding. Theoretically, 'diffusion of innovations' is concerned with why, how and the rate at which novel ideas and innovation spread. Rogers (1995), indicates that diffusion of innovations define show an innovation is transferred over time amongst people. The theory of diffusion of innovation potentially, has used innovation ideas, artefacts and techniques, as the hypothetical basis for some innovative explorative projects(Rogers 1995; Bakker 2015; Roncaglia 2013; Yates 2001).

According to Rogers (1995), four factors influence the diffusion and adoption of innovations. These are; information about the innovation itself; method of innovation transfer; time used in spreading the innovation; and the society the innovation will be transferred. For Prieto (2013), the 
spread of innovations and the applications adapted to spread the innovation should be closely knitted to the local context. When an innovation is diffused without considering the norms and values of the people and already existing innovations, it can result in low adoption rates. Before and after information on innovation diffusion in a society is significant to high adoption rates.

Using such before and after information from end users, new or improved innovations can easily be disseminated. To develop an innovation, it is vital to understand and know the channels of innovation and how end users can easily adopt such innovations. This shows that where new innovations are diffused, people will adopt or reject the innovation based on the limitations identified at the initial stages. Rogers identified two ways in which behavioural change can occur during innovation transfer. The first behavioural change is imminent change. Imminent change happens within and between members of a social system. The second, behavioural change was identified as contact change. Contact change occurs where external sources to the system introduces new innovations (Rogers 1983; Rogers 1995).

In behavioural change, time is essential. Rogers (1995) disclosed that an important aspect in the diffusion process is time, which is mostly over looked in behavioural studies. When there is time to fully understand an innovation, adoption rates are mostly high. Langyintuo et al (2000) argues that the innovation-diffusion model holds that access to information is key to determining adoption decisions. If an innovation is suitable, the problem of adoption is reduced to transferring the innovation to the possible users (Langyintuo et al 2000). Prieto (2013) indicates that this is made possible because, farmers and scientist share knowledge regularly among and between themselves and more especially scientists are considered agents for the diffusion of knowledge. This is confirmed by Bellwood (2017) who argues that agricultural technologies can only spread among its practitioners, than by widespread in situ adoption. This is a kind of technological solution to the problems of technological dissemination that might give people more knowledge about a new innovation making them more competitive (Prieto, 2013). So when knowledge is disseminated to people it will not simply lead to behavioural change but also well inform decision making.

An element of the diffusion process which has not been widely researched is discontinued adoption. Discontinued adoption occurs when the use of an innovation is stopped after haven been adopted before (Inaizumi et al 1997). Rejecting an innovation can occur after the introduction of more effective innovations, ineffectiveness or lack of information. According to Gedikoglu (2010) there have not been any theoretical models of innovation dis-adoption until his study on the, Impact of Farm Size and Uncertainty on Technology Dis-adoption. Gedikoglu suggested that large-scale farmers were more likely to dis-adopt an old innovation if the cost of replacing an old innovation with a new one is the same.

For effective innovation dissemination, Agricultural extension is an important channel of innovation dissemination (Sumberg and Okali 1997). Research and extension workers are primarily responsible for identifying and introducing new agricultural innovation; typically categorized as a top-down process of technology development, transfer and adoption. Here, researchers develop the innovation, extension workers transfer the technology to farmers who decide whether or not to adopt or reject the innovation based on the features of the innovation. The agricultural extension service is the bridge between modern techniques and farmers. They offer practical demonstrations in disseminating innovations to rural farmers (DateBah 1985). Farmers who are regularly in contact with agricultural extension agents are more likely to adopt new and improved innovations because they are exposed to new innovations.

Other factors that influence technology adoption include age, farming experience, training received, socio-economic status, cropping intensity, aspiration, economic motivation, innovativeness, information source utilization, information source, agent credibility and adoption (Inaizumi et al 1997). Innovation dissemination is either through formal or informal process. As a result, individuals go through this process more often than not in their daily lives.

Bellwood (2017) regards agriculture innovation as a comparatively uncommon human development that, once developed, has significant abilities to expand through its adoption. According to Rogers (1983) when an innovation is adopted the individual recognises the new innovation as an improvement over the old innovation. An outline of an innovation-decision path shows that an individual would have to have first knowledge of an innovation. The innovation is implementation which leads to confirmation of the decision to adopt or not (Rogers 1983). The innovation decision path can lead to a decision to entirely use the new innovation as the best alternative available, or reject it. It is however also possible for an adopted innovation to be rejected after a previous decision to adopt it or vice versa (Rogers 1983).

The successful adoption of innovations entails an in-depth understanding of the technical concepts used and a multidisciplinary method to understanding the complex nature of the farming systems, farmer's environment and decisionmaking process (Nagy and Sanders 1990). Nagy and Sanders contend that agricultural scientists do not often explore the complex systems and farmer's needs in carrying research. Where farmers do not adopt recommended innovations, the first reaction of the agricultural scientists is usually that the problem is with the farmers, the extension service, or national economic policies, than the suitability of the innovations (Nagy and Sanders 1990).

The length of time impacts on the adoption rates. The term, adoption rate refers to the comparative speed that members of different social systems adopt an innovation. The rate of adoption 
model shows that adoption of an innovation is usually slow but with time, more adoptions are achieved (Rogers, 1983; Roncaglia 2013). Adoption rate is often measured by the amount of time required for a number of people to adopt an innovation. However, different social systems exhibit different adoption rates for the same innovation (Rogers 1983).

Socio-economic assessment study suggests that farmers necessarily do not adopt innovations fully but rather, parts are adopted (Lawrence, Sanders and Ramaswamy 1999; Nagy and Sanders 1990). There are suggestions that farmers hardly position themselves to adopt complete packages because of risk aversion and lack of resources. The adoption of new innovations does not happen all at once, but a little at a time depending on some factors. Innovations are adopted based on factors such as profitability, riskiness, initial capital requirements, complexity and availability in a stepwise pattern (Lawrence, Sanders and Ramaswamy 1999; Nagy and Sanders 1990; Song et al., 2017; Wu, 2017). The innovations that meet the above factors are seen as the best options. Additional components are considered if the experience from the first is positive. While new innovations are disseminated to farmers as a 'package', they adopt parts of the innovation over time, in a logical sequence to their perceived needs. In focusing research, extension, and government programs that aim at setting priorities for government policy and innovation adoption, information on the likely adoption pattern sequence of innovations is important (Lawrence, Sanders and Ramaswamy 1999; Nagy and Sanders 1990).

\section{Research Location and Sources of Data}

This paper draws on data collected during a fieldwork in northern Ghana. The northern region, one of ten regions of Ghana, has 13 districts. This study was conducted in two of the districts from which two communities, Kpasa and Tamalbila were selected. Kpasa, and Tamalbila. Tamalbila is located in the Tolon Kumbungu district and had a population of around 1000 while Kpasa, had a population of about 800 is located in the WestMampusi district. The two study communities are predominantly agriculturally based, and rely on farming as a major source of income and food for household consumption.

The research was conducted in confidentiality: participants' rights and privacy were respected. Confidentiality was maintained by concealing the identity of communities and research participants under study. Clear information and assurances was given to participants on data protection, which was categorically read out to participants.

The following methodology aimed to collect data to explore the relationship between gender, group formation, mobility, age and innovation transfer.

\section{METHOD}

\section{Methodology, Sampling Procedure and Data Collection}

Semi-structured and open ended questionnaire were used. Thirteen cowpea growing communities involved in the cowpea IPM FFS were identified as Kasalgu, Tampie-Kukuo, Malsheigu, Kumbuyili, Gumo, Nwodua, Kpenjing, Cheyohi, Nwangbong-Yepala, Walewale, Logri, Kukua and Yendi. From the sample of 13 communities, two communities were randomly selected using an online random choice generator. The actual names of the communities involved were changed to Tamalbila and Kpasa; these are pseudonyms. The communities under study are small communities where everyone knows everyone else. To protect respondent confidentiality, pseudonyms were use.

Seven household were observed in the study communities; three in Tamalbila and four at Kpasa. Households that had been involved in agricultural development programmes with Agricultural Development Agencies in the Northern Region were numbered and randomly selected using an online random choice generator. Observations were structured to capture major points of interest such as technologies used by members of a household in the agricultural and non-agricultural sector. A total of 120 individual interviews were conducted for the formal survey guided by the questionnaire while 200 community members (Table 1), including male and female farmers, elders and mostly female cowpea traders were involved in five Focal Group Discussion (FGDs) Workshops. The individual interviews were targeted at household heads or their representatives but the female respondents were either household heads or asked to be interviewed in place of the household head. Three FGD workshops were held in Tamalbila and two FGD workshops in Kpasa. Cowpea farmers were used because the three agricultural development agencies have done extensive work together on cowpea. Data was collected on current and new agricultural practices, technologies adopted, rejected or discontinued, linkages with other social group within and outside the study area, formal and informal methods of technology transfer, how long farmers have adopted new/improved technologies, number of people technologies have been transferred to, group belongingness and how group formation has impacted on technology uptake or transfer among other questions. Demographic information was collected on age, education and years of experience in farming.

Data obtained by the questionnaire, observations and FGDs were analyzed using NVIVO. Nvivo was used to describe participants' opinion, identify similarities, create generalizations, extract themes, highlight differences and identify relationships. Data was divided into meaningful units by manual coding to nodes and separate nodes were used for each element or concept. 
Table 1: Participation in Interviews and FGD Workshops

\begin{tabular}{|l|c|c|}
\hline Community & Individual Interviews & Focal Group Discussions \\
\hline Tamalbila & 60 & 100 \\
Kpasa & 60 & 100 \\
Total & 120 & $\mathbf{2 0 0}$
\end{tabular}

\section{RESULTS}

\section{Group Formation and Innovation Adoption}

The cowpea FFS groups today consist of farmers from the same community and of the same gender, thus enabling easy discussions among members. Farmers who already belong to a group in the villages are a starting point for agricultural development agencies during the FFS. Farmer groups are predominantly small. Members meet to discuss issues of common interest. For instance in Kpasa, the vegetable farmers group, which consists of only females, meets to discuss the best ways to cultivate and sell their produce. In such a case extending techniques on vegetable production will not be a difficult task for the three agricultural development agencies. Again where one of the group members knows of a new agricultural innovation, it becomes easier to spread information to others within the group.

Group formation has brought with it recognition of the farmers by the institutes in terms of collective reaction to the dissemination of new innovations which is also cost effective. Group formation is where a group of interrelated people come together to form a group with the aim of achieving a common interest. As a result, the importance of groups' adoption of new agricultural innovation has long been of interest to agricultural extension staff, sociologists and economists. Mostly agricultural development programmes target preexisting groups. The use of pre-existing groups softens the burden of involving farmers especially women in FFS and thus ensures their effective participation. Commenting on the involvement of women in the FFS, Salif, a-34-year-old male farmer from Kpasa said,

'It is often difficult involving women in dissemination programmes as they are occupied throughout the day but where women are already in groups, they can decide among themselves who should get involved. This allows them to plan around their activities to attend programmes like the FFS.'

This is an indication that it is not always the fact that men are preventing women to attend dissemination programmes. Women are already working in groups and can decide among themselves who will attend an innovation dissemination programme. On the other hand, men can also relieve women from their workload to allow them to participate in innovation dissemination programmes; such as the cowpea FFS. This is because men/husbands are beginning to realise the importance of women in the agricultural sector. If a woman has knowledge in the use of new agricultural innovations, her output towards her family's agricultural productivity increases.

The farmer-to-farmer transfer of the cowpea IPM techniques is very important for farmers as it facilitates learning through information sharing among members. The fact that knowledge of the cowpea IPM strategies may be disseminated to groups of farmers outside the FFS structure is significant to innovation adoption. So the linkages between men and between women point to a potential for sharing within and between families and villages. Sharing the knowledge acquired during the FFS is encouraged through kinship ties, friendship and familiarity with close neighbours. Knowledge shared during the FFS include scouting for insects and determining the threshold levels at which neem and or chemical pesticides should be used, planting regimes, weeding, time to harvest and modes of drying the cowpea grain. Thus FFS graduates become de facto role models as groups of farmers in their villages see them as knowledgeable and may invite them to share with them their experience. This is evident from this study where 14 males and seven females of the main interviews at Tamalbila had transferred knowledge and experience of the cowpea IPM techniques to about 15 other farmers each since 1999. In Kpasa 18 males and six female respondents involved in the main interviews had transferred to at least ten farmers each, since 2004.

In effect, 240 farmers from Kpasa and 315 farmers from Tamalbila have benefitted in one way or the other from farmer-to-farmer training on cowpea IPM techniques, as well as those who were trained directly through FFS. If these 555 farmers were to transfer their newly acquired to other farmers, along with the 45 original participants who will also continue to transfer to colleagues and family members, it means that within a short time there is the potential for almost every farmer in the community to adopt improved cowpea IPM innovations. This demonstrates the value of the FFS approach. Though some farmers transfer on an individual basis, the majority of farmers do group transfer of cowpea IPM innovations as they learnt through their own cowpea FFS. The FFS 'graduates' may be invited by members of already existing farmer groups for training on cowpea IPM techniques. This process points to the importance of the good training for which the Farmer Field Schools are renowned. It is not simply a teacherstudent learning process but rather a group learning process in a practical field setting. This 
Farmer-to-farmer transfer of cowpea IPM techniques is not only done in the villages where the cowpea FFS took place but are extended to nearby villages.

Farmers who have the FFS experience of working in groups are also able to develop confidence in putting across their ideas in ways that promote positive attitudes towards joint achievement of goals. Thus all the female farmers at Kpasa expressed the view that working in a group promotes success and ensures task completion.

Government representatives together with opinion leaders, usually the chiefs and elders, also leaders of farmers' associations and women's groups, in the initial preparation of the FFS process indeed have a great impact on the diffusion of innovations in the communities. Opinion leadership reflects the ability to influence the attitudes and knowledge of others. Opinion leaders in the research sites tend to have higher social status, income or wealth than others in the community and are often more exposed to external sources of information, such as that from the three agricultural development agencies. From the two main study villages, opinion leaders influence community development and the adoption of innovations because they come together with community members to agree on which community development projects and agricultural technological programmes are good for their village. As such, opinion leaders are said to have the status, expertise and links to external sources of experience that enable them to provide information and advice about community development and innovations to others within their community.

Results showed that to achieve effective agricultural development, it is common practice to contact community farmer groups to first boost the participation of male and female members. This gives both men and women the opportunity to influence the activities of the three agricultural development agencies and there is a greater likelihood of achieving higher rates of dissemination and adoption of cowpea IPM techniques. Where women from different social strata in the community are involved in one women's group or the other, the likelihood of targeting a wide range of farmers from different social backgrounds will be very high. This is because every social stratum is present in a farmers group and will be involved once they are engaged in farming and part of the targeted group. Adamu, a 57-year-old farmer, trader, widow, group leader and household head from Kpasa, indicated that her group members see themselves as one and forge ahead in self-help, rather than waiting for support.

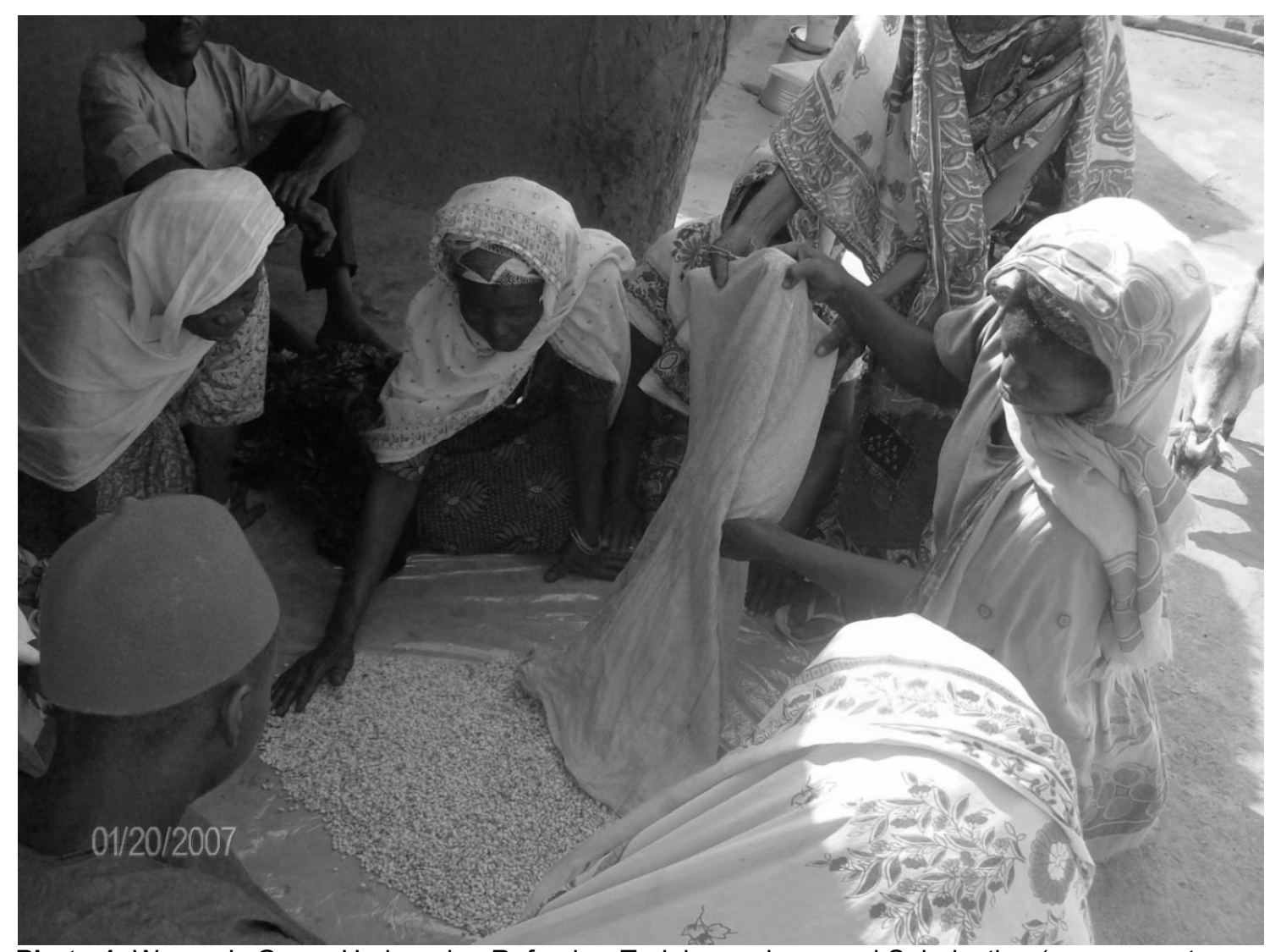

Photo 1: Women's Group Undergoing Refresher Training on improved Solarisation (a cowpea storage innovation) from Men in Kpasa.

Source: Field Data 
There is also a cycle of innovation transfer and adoption as members of the FFS groups are open to learning from each other as in Photo 1. Groups that are involved in the FFS learn how to do innovative experiments during and after, like scouting for insects and determining the insect threshold levels at which chemical pesticides and or neem should be sprayed. Thus they are enabled to develop a shared vision, define common objectives, promote basic planning among themselves and record keeping, build mutual trust and responsibility, resolve conflict and sustain their learning process. Tiana, a-55-year-old male farmer and household head from Tamalbila made known to me that,

'People gather together to share ideas which are often transferred through general conversation or semi-organized demonstration of cowpea IPM innovations. Those who do not know the innovations then have a chance to ask questions.'

In forming the groups for FFS, participants are often aware that research and extension organisations need their participation for carrying out activities. To promote participatory decisionmaking, about a third of respondents of the two main research villages indicated that the organisers of the FFS often select in advance those who can offer interviews and participate in-group activities.

Self-help groups also facilitate the diffusion and adoption of innovation. Cowpea farmers in Tamalbila are involved in self-help groups. Selfhelp groups provide a setting in which farmers come together to share similar experiences through practical support in a reciprocal and mutually beneficial way. These groups are informal groups and formed based on shared interest where membership is open and voluntary. According to Adamu from Kpasa, such groups enhance the continued adoption of innovations as farmers remind themselves of the best practices to protect their cowpea plants and grain from insect infestation. Farmers are admitted into self-help groups based on their social relationship with other members of the community at large, and can belong to more than one group. For instance, Agana a-65-year-old male farmer and household head from Kpasa said that when women meet they encourage those whose innovations are not working, and also come up with new ideas on how to make them work better. Overall, groups are popular in these villages and must be seen as part of the communication network for men and women but possibly especially for women.

\section{Labour, Mobility and Innovation Adoption}

The mobility of people from rural to urban communities during the non-farming season will continue, due to the north-south divide, until the disparities between the two social settings are remedied. Azee, a-42-year-old female farmer from Kpasa commented,
'You see we are very poor people here. So to improve on our wellbeing, we have to travel to the city in search of a better life. People will always go because their colleague who goes to the city returns well off.'

This shows that farmers travel to the city to ensure a better wellbeing which can translate into the adoption of improved agricultural innovations and hence increased agricultural production and productivity.

The rural areas of southern Ghana are more developed economically and have more opportunities than even the cities of the northern part of Ghana. This distinction has been appreciated by rural dwellers in the study areas that use it to categorize people who have been to the city. If a community is near a city in Northern Ghana, the person who travels to the south of Ghana has more social recognition than those who go to nearby cities. Naziru a-71-year-old farmer and household head from Tamalbila indicated that when someone travels to the south they return with much more amusing stories than someone who has travelled to nearby cities. The south is also believed to be more advanced than the north, hence the development and dissemination of new and improved innovations is more visible than it is in the north of the country. As a result farmers who migrate to the south often return with new ideas and better ways of undertaking farming activities and wanting to adopt more innovations.

The rate at which farmers migrate to the urban areas in search of a better livelihood has been on the rise in the study area. In the main interviews, 70 percent of the farmers interviewed had migrated at some point to the south of Ghana, with 15 percent being women. The reasons for migrating were said to range from working on other farmers farms to renting farmlands and cultivating crops on their own. It is in the process of working on southern farms that farmers learn new innovations said Azumah a-55-year-old female farmer from Kpasa. Azumah further reported that in the past 12 years farmers have been making their own efforts at sourcing and adopting new and improved innovations, having realised their social status and the importance of new innovations notably during the cowpea FFS and other innovation dissemination programmes.

Rising population densities, dwindling farmlands, increased demand for cowpea and pest and disease control in the study areas have also forced farmers to employ new farming techniques, such as the IPM innovations, to increase cowpea production. Farmers from both study villages reported that population densities have indeed increased over the years and has resulted in smaller farms for the residents of Kpasa and Tamalbila. In response, the farmers in the two main study villages turn to migration as a subsistence strategy; they go in search of both agricultural and non-agricultural jobs to earn more income for their families. Farmers from Kpasa reported that when 
rural farmers migrate to the cities for jobs they tend to urbanize themselves, which encourages the adoption of new innovations. There were indications that Urbanization has an influence on innovation adoption. Most of the early adopters of the cowpea IPM techniques were those who had migrated at some time to the south, and returned.

Out of the 120 respondents of the main study, 34 men and 12 women from Tamalbila had migrated at some time to the south of Ghana, whereas migration figures respondents from Kpasa stood at 20 men and six women. These 72 farmers were among the very first to adopt the cowpea IPM techniques on their own farms having participated in the cowpea FFS. This suggests that those who migrate and return are more willing to adopt than those who remain in their village - either because they have seen the benefits of adopting agricultural innovations elsewhere and are keen to apply them at home or because they are more modern/innovative people. Furthermore, because of the increased social status they are given on their return they are referred to as the 'village champion' because they have been exposed to new ideas in the rural south or in the city. For instance, Abdul, a-60-year-old male farmer and household head from Kpasa, said,

'When one migrates to the city and returns, it is believed that you have 'seen' the world and that innovations are good and, for that matter this is confirmed because you are the first to adopt. Such farmers who visit the city are also the first to get involved in diffusion programmes such as the FFS.'

The rate of adoption of new farming methods especially cowpea IPM techniques in Tamalbila is higher than in Kpasa in recent years. In Kpasa farmers had transferred IPM and other relevant agricultural innovations to 240 farmers whereas in Tamalbila these innovations were transferred to 315 farmers. This, Azumah a-55-year-old female farmer from Kpasa, explained, is due to the rate at which farmers migrate to the city and the cities they migrate to. Farmers in Kpasa mostly migrate to cities both in the north and the south of Ghana as compared to farmers from Tamalbila who migrate further south. This could also be due to differences between the two villages such as size and the distance from the urban area, even though Kpasa used to be more innovative.

This means that innovation transfer can be indirectly supported by migration. For instance if the organisers of the FFS were aware of the importance of migration for the capacity or willingness to adapt or change they could have selected such farmers to participate. This would have strengthened the potential for successful outcomes from farmer participation, both innovation adoption and farmer-to-farmer transfer. However, it must be noted that in fact, most of the FFS participants had previously migrated and so adoption rates and farmer-to-farmer transfer of the IPM techniques have been encouraging overall.
A majority of the respondents from the main study villages agreed that rural urban migration influences the likelihood of innovation adoption. Finally, it was made known to me that the first few people to be involved in the cowpea FFS, and who elected to be lead adopters, were among those who had ever migrated to the south of Ghana. Organisers of the cowpea FFS did not ask for such farmers to lead the groups but because of their self-esteem among their colleagues, they were elected.

Remittances from absentee household members, was also found to function to facilitate adoption of agricultural innovations. Some improved innovations such as the use of improved solarisation, and frequent scouting of the cowpea crop under the cowpea IPM techniques can be expensive and time consuming. So, with remittances from relatives who have migrated and managed to earn sufficient money, farmers can buy materials and other resources such as bicycles to save time travelling to and from farms, which can translate into innovation adoption and improved yields. Reports from Tamalbila indicated that friends and family who have migrated to the urban communities were found to be important sources of financial and social support for people to have a better life thus aiding agricultural production.

Mobility is also thought by farmers in both Tamalbila and Kpasa to reinforce a pattern of dependent community development, whereby higher living standards are achieved through the inflow of monies from wealthier areas rather than the expansion of economic activities from home. Informants from Tamalbila however, reported that higher living standards have a positive influence on the use of cowpea IPM techniques under the FFS. Reports from informants indicated that the effect of mobility is two sided. The immediate downside is that rural communities lose some labour due to mobility of boys and men and in some cases women, which particularly affects the implementation of improved innovations that are labour intensive. However, the informants from Kpasa notably reported that if labour can be paid for, and there are remittances from family member who are in the city, farmers back in the rural villages can buy inputs to practice the new and improved innovation. This means that some people will prefer some members of their family to travel to the city in search of money for them to have access to agricultural inputs and improved innovations to improve on agricultural productivity.

Learning through observation for innovation transfer is also very important. Sanatu, a-40-yearold cowpea farmer and trader from Tamalbila, residing in Tamalbila sells cowpea to cowpea sellers at the Tamale market. The cowpea sellers at the urban market then sell to consumers. Sanatu described how these urban cowpea sellers have a skill of storing cowpea until it is needed and confirmed that she has attempted to find out what they do so that she herself can then apply their techniques to her own stored cowpea. This suggests that new agricultural innovation is likely to 
be found in the city.

In the same light, FFS's are most often strategically located not far from a major road so that other farmers may see what is happening during the training. This draws farmers into thinking about how cowpea IPM innovations are important in cowpea production. As a result they end-up wanting to know more about the innovation being disseminated. These farmers could be from the same community as the participants of the FFS, nearby communities or relatives and others from far away communities.

Nearness to the city also encourages increased productivity as farmers can easily take their produce to the city to sell because demand and prices are higher in the cities. Thus there is the incentive to grow more cowpea and store it better. A majority of the respondents from the two main study villages thought access to markets in the cities was an important incentive for encouraging the adoption of improved innovation. This is because farmers will want to adopt innovations that can help them produce sufficient both to feed their families and to have surplus to sell and buy farm inputs for the following season. Without a good market farmers find it difficult to continue to adopt improved innovations such as improved solarisation, one of the cowpea IPM innovations. Thus, there is an argument that it is the demand for farm produce from the city dwellers which acts as a driver for farmers to adopt innovations that improve productivity and crop quality. This is the basis on which agricultural development agencies develops and improves new cowpea innovations that are transferred to farmers, thereby meeting the demands of both farmers and (urban) consumers.

It became clear from the interviews that the farmers in the research locations consider new innovations to be more efficient than older ones because they have observed increases in productivity as a result of the use of innovation. According to Abdul, a-50-year-old male farmer and household head from Kpasa,

'For the majority of us, new agricultural innovations are working for us as we perceive them to be better than 'old' innovations but the new ones are often much more expensive so it takes us time to adopt them.'

This shows that people adopt new agricultural innovations at different times and for different reasons. Though existing agricultural innovations are 'tried and tested', some farmers still prefer new innovations due to their effectiveness. Farmers sometimes argued that this is because 'new' innovations are developed when the 'old' ones become less effective or when someone comes up with an idea better than a previous one.

The number of farmers using IPM techniques in Kpasa in the past five years has more than doubled, according to 27 (18 males and nine females) of the respondents. These farmers argued that this reflects migration to the south of Ghana where innovations are likely to be tested first. As a poorer village compared to Tamalbila, most farming households in Kpasa are compelled to engage in migration to the south of Ghana to farm. These farmers get used to working with new techniques and so adopt them on their return home. However there are constraining issues such as misinformation, inefficient communication, lack of practical demonstration and lack of finance, as some of the respondents explained. Five women involved in the group discussions in Tamalbila argued that some farmers may implement new innovations just on the basis that they have heard other farmers discuss them without actually undergoing proper training on their use. This might best explain one of the several patterns of innovation transfer, adoption and dis-adoption. However, a majority of the respondents from the two main study villages confirmed that most people who migrate to the south have successfully adopted and transferred to others new methods of farming on their return and this pattern is not limited to the cultivation and storage of cowpea. For example, cocoyam, plantain and banana are farmed in large quantities in some parts of northern Ghana even though the cultivation of these crops in the north: is unfamiliar the northern farmers who migrated to the south brought these crops back with them.

The period of time that one lives in the south, either in a city or in a rural area influences innovation adoption: Those who go to the south, even temporarily, adopt innovations faster than those who have never been south. It was confirmed by respondents that farmers who are the first to adopt the IPM techniques are those who have lived in the south before: Of the 60 respondents in Tamabila, nine males and two females confirmed that not only were they the first to adopt the IPM techniques, they had also lived temporarily in the south. Similarly, in Kpasa, 15 males and five females who were the first to adopt the cowpea IPM techniques were also among those who had lived temporarily in the south.

Aside from temporarily or permanently living in urban settings, other farmers may go to the urban areas on a regular basis such as Sanatu the farmer- trader mentioned earlier and this also impacts on innovation diffusion. Such farmers hear and discuss what is happening elsewhere and by doing so they develop interest in different innovations which they intend to adopt. Fifty four of the respondents reported on these processes of information exchange and its importance for their adoption decision-making.

Seeing for oneself is very important in terms of making a decision to adopt an innovation. When people see, observe and discuss what is happening around them and in new environments, their ability to make decisions is usually based on concrete evidence of the efficiency of the new method. Findings from the research indicates that as people move around they look around and observe what others are doing, which has the 
potential to significantly affect their interest to adopt.

Despite the important role mobility plays in innovation dissemination and adoption, it comes with consequences. Fifteen of the respondents from Tamalbila, five females and 10 males, argued that there are others who return, not so much with good ideas, but with all sorts of social vices, such as drunkenness, smoking of marijuana, cultivating the habit of casual sex and robbery which are then spread to others in the villages. Mention was also made of the spread of sexually transmitted diseases. This shows the perceptions of negative impact of modern urban life on rural villages. However, a majority of the respondents interviewed at the two main study villages explained that the positive impact of migrating to the urban areas far outweighs the negative, as households that have their members in the cities have a lot more farm equipment. They further explained that 'when people who migrate return, other members of their communities admire them, get close to them and copy their new ways of life,' (Ababa, a-50-year-old male farmer from Kpasa). In response, Amadu, a20-year male student from Kpasa, said that,

'Those who go to the city might have brought back with them skills for life, but there are some who return with unwanted pregnancies and HIVIAIDS. Some have returned with children whose fathers cannot be traced, thereby imposing a burden on their parents.'

This, Amadu felt, was the consequence and burden for many young women who migrated. Amadu is witness to this kind of situation in the urban community as men of his age are those who migrate to the cities.

\section{Age and Innovation Adoption}

It is evident from the data that most of the informants adopted new and improved cowpea innovations no matter their age. Out of the 120 respondents who participated in the main interviews in the two study villages all but three are using some cowpea IPM techniques (Table 2). All three are from Tamalbila and all were between the ages of 56 and 72 years old (Table 3). Amongst this group of farmers, even though the younger farmers do not have the same years of farming experience, they adopt innovations faster than older farmers, possibly due to their exposure to innovative methods of farming outside the rural farming settings.

Table 2: The Adoption of Cowpea IPM Techniques by Age and Gender

\begin{tabular}{|l|l|l|l|l|}
\hline \multirow{2}{*}{} & \multicolumn{2}{|l|}{ Tamalbila } & Kpasa \\
\cline { 2 - 6 } & $\begin{array}{l}\text { Total no. Of } \\
\text { Respondents }\end{array}$ & $\begin{array}{l}\text { Numbers Adopting } \\
\text { IPM Techniques }\end{array}$ & $\begin{array}{l}\text { Total no. Of } \\
\text { Respondents }\end{array}$ & $\begin{array}{l}\text { Numbers Adopting } \\
\text { IPM } \\
\text { Techniques }\end{array}$ \\
\hline Men & 30 & 26 & 30 & 30 \\
\hline Women & 20 & 18 & 20 & 20 \\
\hline Young farmers & 10 & 10 & 10 & 10 \\
\hline Total & $\mathbf{6 0}$ & $\mathbf{5 4}$ & $\mathbf{6 0}$ & $\mathbf{6 0}$ \\
\hline
\end{tabular}

Source: Field Data

Abuba, a-50-year-old farmer and household head from Kpasa argued that,

'We the older people do not adopt innovations just like that despite our experience in farming activities because we are used to our local innovations. It is the youth who adopt any innovation that is introduced to this community. This can be because of their exposure to new innovations in the cities.'

However, this study indicated that almost everyone adopted (Table 3) some elements of the cowpea
IPM strategies, at different times. Most farmers did not adopt the cowpea IPM innovations as a whole but chose the elements that suited them or that they could afford. Since the innovation and expected return were based on the whole package the piecemeal adoption results in inefficiencies. However, it must be noted that the part that farmers adopted appear to have met their expectations in terms of effectiveness. Tampuri, a-54-year-old male household head from Tamalbila argued that young farmers and women have been the first to adopt the cowpea IPM innovations followed by the middle aged and the elderly. 
Table 3: The Adoption of Cowpea IPM Innovations by Age

\begin{tabular}{|l|l|l|l|l|l|l|l|}
\hline $\begin{array}{l}\text { Age of } \\
\text { Respondents }\end{array}$ & \multicolumn{2}{|l|}{ Not adopting IPM } & \multicolumn{2}{l}{$\begin{array}{l}\text { Adopting two IPM } \\
\text { techniques }\end{array}$} & $\begin{array}{l}\text { Adopting most IPM } \\
\text { techniques }\end{array}$ & Total \\
\cline { 2 - 8 } & Men & Women & Men & Women & Men & Women & \\
\hline $56-75 y$ years & 4 & 2 & 20 & 0 & 0 & 6 & 32 \\
\hline $35-55$ years & 0 & 0 & 16 & 0 & 14 & 26 & 56 \\
\hline $18-34$ years & 0 & 0 & 0 & 0 & 26 & 6 & 32 \\
\hline Total & $\mathbf{4}$ & $\mathbf{2}$ & $\mathbf{3 6}$ & $\mathbf{0}$ & $\mathbf{4 0}$ & $\mathbf{3 8}$ & $\mathbf{1 2 0}$ \\
\hline
\end{tabular}

Source: Field Data

To understand the behaviour in adopting new innovations it was useful to categorize the informants by age as follows: young farmers aged between 18 and 34; middle aged farmers between 35 - 55 old and elderly farmers between $56-75$ years old. The young farmers who were mostly male were rarely household heads and did not play any role in making decisions for the upkeep of the households; they are answerable to the household head. However, young men farm together with other household members, and also on their own so are able to make farm management decisions on whether or not to adopt improved agricultural innovations. The middle aged farmers could be divided into two categories, those living in the wider family compound possibly assisting older family heads make decisions, or those who have broken away from the larger family compound. Though this is rare, there were four such households in Tamalbila. The elderly were few in numbers.

It is also important to consider gender when looking at the link between age and behaviours. In the case of this study all the women adopted the new innovations regardless of their age. It was the older men who were less likely to adopt. Women's adoption of innovation has been compared by respondents from the development agencies to the adoption of innovations by young male farmers. Interviews showed women and young farmers as the main adopters. Young farmers and women adopt innovations faster than men, though men could be vocal and participatory, but behind the scene, the women could be doing the right thing and adopt innovations rather than men.

It is therefore argue that this can be traced back to the important role that women play in agricultural production, where women together with men undertake farm activities. So, to enhance their productivity and to improve on the standard of living of their children and families, farm households are inclined to adopt new and improved innovations. Tampuri, from Tamalbila argued that young male farmers see innovation as the order of the day and so will experiment with any innovation thrown at them. According to Amadu, a-20-year-old male farmer from Kpasa, young farmers adopt new agricultural innovations because they are the ones who together with the women and the middle aged are mostly involved in agricultural activities. He further explained that, most young farmers would be planning to marry and will have to adopt new innovations to increase their agricultural productivity: Increases in agricultural productivity result in increased income and with increased income the male young farmers has the needed resources to marry.

Out of the estimated 555 farmers who had received farmer-to-farmer training on cowpea IPM techniques from the original cowpea IPM FFS participants, 55 percent are female, 35 per cent are young male farmers and 10 percent are middle aged and elderly farmers. Based on these figures it would seem to be worthwhile engaging a greater proportion of women and young male farmers in future IPM programmes, as they are likely to adopt faster, and in turn transfer faster.

This study suggests that older men find it difficult to change their farming practices. In the view of five women from Tamalbila, older people (who are also custodians of knowledge) in rural communities are more attached to traditional norms and values of their communities, and are therefore very reluctant to accept change, which makes it very difficult for them to adopt new innovations. Some eventually do adopt innovations but it takes a longer time for them to adopt. They tend to observe the experience of others before entrusting their resources in the use of such innovations.

Where an innovation that is being used has been disappointing, farmers (including older farmers) are more likely to try innovations. Despite the adoption of improved innovations, some farmers, especially the older ones, use some of the local innovations to keep their traditions alive and also as a source of information to their children.

Middle aged farmers clearly adopt innovations but also like their elders seem to want to think about it before making a decision. In this case, they have a family to look after and would want to think carefully about the issue of cost and benefit before delving into adopting an innovation. They may try it out first on a small scall. Hudu, a40-year-old male farmer from Tamalbila described his decision making process:

'I have a family to look after so I cannot keep doing trial and error on innovations to find out if they are effective or not. I will rather wait for other people to try it first. My resources are not much and I have a family to look after. That is why my wife and I have resorted to family planning, which most people in this community have refused to practice.' 
As the middle aged think carefully about innovations before adopting them, they are very unlikely to discontinue their use said Tampuri from Tamalbila.

Nevertheless, adoption rates among the middle aged appear to be higher than amongst older people. Findings from the research indicate that of the 120 respondents of the main interviews from Tamalbila and Kpasa, 16 fell within the oldest age category. The study indicated that men in this age category, though are adopting the cowpea IPM techniques, took time in adopting the techniques. Two of the male farmers in this category in Tamalbila did not adopt any cowpea IPM technique though they had participated in the cowpea FFS. These two farmers commented that they were not adopting new IPM techniques as they find old or local innovations effective. However, all the women in the older age category are adopting the use of most of the cowpea IPM techniques with the exception of Ayi, a-70-year-old female farmer from Tamalbila who indicated that she would not change her practice: 'I use only local storage innovations for storing my grain and seed'. Katali, a-35-year-old female from Tamalbila speculated that Ayi had been influenced by her husband.

Those who adopt new and improved agricultural innovations among young farmers have different characteristics from older farmers. This category of young male farmers is prepared to be daring and to take risks, particularly if they control a substantial amount of finance from having moved to the cities during the off-season to seek nonagricultural jobs. The fact is that most of them in the sample were not yet married, and hence the responsibilities of having to take care of children and wives, are not an issue for them. As they have control of a substantial amount of finances, they have the resources to absorb possible losses from unprofitable innovations.

The high rate of adoption among young farmers also reflects their ability to understand and apply complex technological knowledge. Of the 16 respondents who were aged between 18 and 34 , only three, one from Tamalbila and two from Kpasa, were women and they used most of the cowpea IPM techniques as did the young men. There was no incidence of the use of local cowpea cultivation or storage techniques among this age group. People in this age group frequently move to the cities in search of jobs, including women who might be married. In this sample, the women were all married, but they could sometimes travel to the city in search of jobs. Women who are married and travel tend to be those with grown up children or have a mother or mother in-law or co-wife who can look after their children while they are away. Some men also sometimes volunteer to look after the children while their wives go in search of jobs in the cities.

\section{DISCUSSIONS}

How Gender, Group Formation, Mobility and Age Influence Innovation Adoption
This section discusses findings on the factors that influence innovation adoption. Adopting an agricultural innovation, the research suggests, depends upon a number of factors and these include: age, gender, mobility, being part of a group, availability of inputs and finance, effectiveness of the innovation, the role of traditional norms and values and the level of formal or informal education or what might be referred to as enlightenment.

Results of the study indicated that the FFS groups, farmers groups that existed before the FFS groups were formed and groups that have sprung up as a result of the FFS influence on the uptake of innovation. It was established that the cowpea FFS groups consist of farmers from the same community and same gender. This, it seems, enabled easy and productive discussions regarding the innovation among men and between women. It was also found that farmers who are already members of farmer groups in the villages can be a very effective starting point for initiating innovation transfer programmes. Where farmers came together as a group in order to discuss matters relating to agriculture, it strengthened their capabilities and capacity in the agricultural sector and could influence their adoption of new innovations. Groups that were formed during the FFS assisted other groups to be competent in the use of cowpea IPM innovations. Farmers groups also provide openings to farmers to efficiently play a role in the rural market economy and benefit from it. Amu (2005) and Whitfield (2005) suggested that, programmes under the Ghana poverty reduction programme targeted vulnerable groups which included women's groups. These women were involved in groups of food crop producers engaged in cowpea, vegetable, groundnut and rice production, of which women were a majority. The targeting of these women's groups was aimed at improving the social and economic conditions of women and their productivity as farmers, by involving them in agricultural development programmes.

It was found that the use of pre-existing agricultural groups makes it easier to access women for the FFS. Women are difficult to contact due to the nature of their work and the cultural systems in place. In situations where women have already established their own group activities around agriculture, it becomes easier to identify potential women who would be receptive to the transfer of innovation and who would be well disposed to its adoption and continuing use, but who would also acts as informal diffusers of these innovations as they confer with each other through their daily activities. So when such an opportunity to work with pre-existing women's groups arises, it makes it easier for the three agricultural development agencies to develop effective practice involving women.

With the FFS based on a learner-centred approach, FFS groups were found to be central to the transfer of the FFS approach to other farmers. It was found that during and after the FFS, farmers 
formed their own groups without any prompting or encouragement from the FFS facilitators, to share their knowledge and experiences of the cowpea IPM innovations. By forming into groups it became easier for them to discuss these innovations, to learn from one another, and to share knowledge of their application and potential. In this case, the findings suggest that the farmer-to-farmer approach which involves transferring agricultural innovations to groups or to individual farmers, aided the transfer of the cowpea IPM innovations considerably, and so had positive consequences for their adoption. Through the group transfer of the cowpea IPM innovations, the farmer-to-farmer transfer of the cowpea IPM innovations has enjoyed significant success, and a majority of farmers who had not participated in the cowpea FFS are now practicing these cowpea innovations. This finding is supported by the research literature, which has long indicated that the decisions to adopt agricultural innovations are widely shared by clients and potential adopters where groups are involved (Rogers 1983).

A further significant finding from this research was that there is a considerable movement of farmers from the northern agricultural regions to the south of Ghana, primarily to the cities and towns. With the south being more developed than the north, it seems that farmers moving to the south are more likely to encounter innovations in agricultural techniques and practices, and then to bring these back to their villages when they return: In migrating to the south to improve on their economic and social wellbeing, the farmers encounter innovations in new contexts, and it is this that has a positive impact on their willingness to adopt new agricultural practices. The agencies working in the three villages where the research was undertaken seem to appreciate this and farmers who had migrated to the south were identified as being among the favourites to participate in the agricultural development programmes they were managing. Indeed, the research made clear that this group of farmers are the first to opt in, and also the first to adopt innovations transferred to them.

The findings further show that women and young people are willing adopters of improved innovations while middle aged and older men are more hesitant, for different reasons. For women in particular, I argue that their readiness to adopt new innovations is related to their pivotal role in agricultural productivity, and their reported need for cash income to enable them fulfils their responsibilities. The younger generation also appeared to be enthusiastic adopters of innovations. Important here, then is that one's attitude towards the adoption of an innovation is significantly related to one's perception of the usefulness of the innovation compared to existing practices. As Rogers (1983) suggested, in adopting a new innovation the individual perceives the innovation as better than the idea it supersedes, providing that it is consistent with existing values, past experiences and needs of potential adopters.
The impact of age on attitudes to innovations seemed more complex. The different age groups used innovations but in different circumstances and as a result of different influences. In determining the adoption of an innovation, it is important to understand the differences between younger and older people and the importance they attach to vital factors that relate to adoption of innovations. Thus, age was found to have an influence on the choice, adoption and usage of an innovation. Older people tended to stay with the local innovations found in their locality. However, this was qualified somewhat by findings that also indicated that older people sometimes choose an innovation based on their emerging or changing needs, rather than simply as a result of customs. Here, however, it would take them a longer time to adopt. According to Nnanyelugo et al., (1997) and Inaizumi et al., (1997), there is a positive and significant association between age, farming experience, training received, socioeconomic status and adoption. This suggests that older people are more willing to be trained, which contrasts with the findings which suggest that women and young people are more enthusiastic about innovations and more willing to be trained.

However, Rogers (1983) suggests that earlier adopters are no different from late adopters in age as there is inconsistent evidence about the relationship between age and innovativeness. About half of the 228 studies conducted on adoption and reviewed by Rogers indicate no connection between age and innovativeness. Nineteen percent show that earlier adopters are younger, and 33 percent show that they are older. The findings therefore contrast with Rogers. From the findings it was evident that age has an influence on the choice, adoption and usage of an innovation whereas Rogers argues that there is inconsistent evidence on age and innovativeness. This finding is key to studies of adoption which can influence way in which innovations are developed and transferred.

Also, the research suggests that middle aged farmers do adopt improved innovations, but more cautiously than young farmers. This group would appear to make careful cost and benefit analyses of any innovation before deciding to adopt. This suggests that they are more risk averse and unwilling to risk their finances than young farmers, most likely because they have much greater responsibilities and commitments than young farmers, for whom any unsuccessful adoption of innovation would not have such wider consequences. Thus they spend more time than younger farmers in making adoption decisions.

The secondary literature indicates that an individual, when considering the uptake of innovation, goes through a decision making process which Rogers (Rogers 1983) referred to as the innovation-decision process. Rogers identified that the rate of adoption is influenced by time. Thus the rate of adoption is the relative speed with which an innovation is adopted. Rogers also identified that, initially, only a few individuals will adopt innovations, with a majority eventually adopting 
with time. So the rate of adoption is normally measured by the length of time it takes an individual compared to his/her colleagues to adopt an innovation. He concludes that younger farmers require less time to make decisions to adopt an innovation, followed by the middle aged farmers and finally the older farmers.

Rogers's analogy on adoption patterns relates closely to the findings that relates to IPM innovations and FFS. Some youth and women are often the first to adopt innovations. The remaining youth and women, middle aged and older people eventually also adopt thus steadily increasing the level of innovation adoption. Rogers continues to argue that after some time the rate of adoption of an innovation reduces thus the ' $S$ ' shaped adoption curve. This is true for the study where innovations become less effective and are replaced with new ones. Where they become less effective, the adoption rates reduces thus indicating there is the need to introduce new agricultural innovations.

\section{CONCLUSION}

Discussion in this paper has focused on group formation, mobility and age, while taking cognizance of the influence of gender as a factor that influences innovation adoption. The paper explores how group formation, mobility and age influence innovation adoption.

Group formation was found to positively influence the adoption of new and improved innovations. The cowpea FFS has also been noted to favour farmers groups where farmers were grouped to discuss and share ideas of the FFS process. As a result the cowpea IPM innovations transferred by the three agricultural development agencies are transferred to groups of farmers that usually favour women. This is because women do not easily mix with men at meetings in and around the study area. In a way this was found to solve the problems of having to include women in dissemination programmes. So to reinforce the involvement of women in innovation diffusion programmes and to ensure they successfully adopt innovations; women must be empowered to do so through groups.

The research findings show that mobility facilitates innovation adoption and transfer. In relation to IPM cowpea innovation, people who have ever migrated are not only more likely to adopt new and improved innovations but also to actively work to disseminate them. Findings also showed that people who have ever migrated on their return are quick to adopt and transfer cowpea IPM innovations. This sheds light on the high rates of adoption among farmers in the two main study villages as a majority of young and middle-aged farmers have previously migrated to the south of Ghana, where innovation is frequently tested first.

To promote the adoption of an innovation, age must be critically considered. It has been argued here that young male farmers, and women of all ages, are more ready to adopt innovations than members of other age groups. Middle aged men take a cautious approach to adoption, examining costs as well as benefits of changing farming practices. Older farmers change their practices if there is no alternative to having good quality produce but practice local innovations in the main.

\section{REFERENCES}

Amu, N. J., 2005. 'The Role of Women in Ghana's Economy'. Ghana: Friedrich Ebert Stiflung.

Bakker, M., 2015. 'Facts, Figures, and the Politics of Measurement: The Construction and Diffusion of Remittances as a Financial Flow' in 'Migrating into Financial Market: How Remittances Became a Development Tool.' Orlando, University of California Press. http://www.jstor.org/stable/10.1525/j. ctt1ffjncm.5

Bellwood, P., 2017. 'Early Agriculture in World Perspective' Golson, J., Denham, T., Hughes, P., Swadling, P. \& J. Muke (eds) 'Ten Thousand Years of Cultivation at Kuk Swamp in the Highlands of Papua New Guinea.' Australian National University Press. Moorebank, Australia http://www.jstor.org/stable/j.ctt1trkk6d.8 Accessed 21/10/2017

Bishop-Sambrook, C., 2005. 'Contributions of farm Power to Small holder Livelihoods In SubSaharan Africa.' Africulture and Food Engineering Technical report2.Rome http://www.fao.org/docrep/009/a229e/a229 e00.HTM Accessed28/11/2010

Date-Bah, E., 1985. 'Technologies for Rural Women of Ghana: Role of Socio-Cultural Factors'. In Ahmed, I. (ed) Technology and Rural Women: Conceptual and Empirical Issues. London: George Allen and Unwin, 7:211-251.

Davidson, J., 2016. 'Rice and Revolution: Agrarian Life and Global Food Policy on the Upper Guinea Coast' Knörr, J. \& C. Kohl (eds) 'The Upper Guinea Coast in Global Perspective' Berghahn Books. Oxford, UK http://www.jstor.org/stable/j.ctt1kk66c1.13 Accessed 21/10/2017

Gedikoglu, H., 2010. 'Impact of Farm Size and Uncertainty on Technology Disadoption.' Selected Paper Prepared for Presentation at the Southern Agricultural Economics Association Annual Meeting. Orlando, FL. http://ageconsearch.umn.edu/bitstream/564 31/2/Impact\%20of\%20Farm\%20Size\%20a nd\%20Uncertainty $\% 20$ on $\% 20$ Technology \%20Disadoption\%20Main\%20Text.pdf Accessed 20/07/2012 
Inaizumi, H., Singh, B. B., Sanginga, P. C., Manyong, V. M., Adesina, A. A and Tarawali, S., 1997. 'Adoption and Impact of Dry-Season DualPurpose Cowpea in the Semiarid Zone of Nigeria', Nigeria: IITA.

Kumar, P., Lorek, T., Olsson, C. T., Sackley, N., Schmalzer, S and Laveaga, G. S., 2017. 'New Narratives of the Green Revolution. 'Agricultural History, Vol. 91, No. 3, pp. 397-422 http://www.jstor.org/stable/10.309 8/ah.2017.091.3.397 Accessed: 21-102017

Langyintuo, A. S., Gyasi, K. O., Abatania, L. N and Terbobri, P., 2000. 'Farmers Strategy for Sustainable Food Security: Determinants of the Adoption of Improved Rice Varieties in the Inland Valleys of Northern Ghana: A Tobit Model Application.' Bamako: SADAOC Foundation.

Lawrence, P. G., Sanders, J. H and Ramaswamy, S., 1999. 'The impact of agricultural and household technologies on women: a conceptual and quantitative analysis in Burkina Faso'. Agricultural Economics, 20:203-214.

Nagy, J. G and J. H. Sanders., 1990. 'Agricultural Technology Development and Dissemination within a Farming Systems Perspective'. Agricultural Systems 32:305320.

Nnanyelugo, D. O., Ngoddy, P. O., Okeke, E. C and Ngwu, E. K., 1997. 'Impact of a Cowpea Research project in Nigeria Using the Rapid Rural Appraisal Technique.' Singh, B. B., Mohan Raj, D. R., Dashiell, K. E. and L. E. N. Jakai (eds) 'Advances in Cowpea Research. 'Co-publication of Institute of Tropical Agriculture (IITA) and Japan International Centre for Agricultural Sciences (JIRCAS), Ibadan, Nigeria.29, 333-340.

PEDUNE., 2000. 'Activity Report.' Working Paper No. 01/99/TR/GH Ghana: International Institute for Tropical Agriculture and Agency for Swiss Development and Cooperation. Unpublished document.

Prieto, L. F., 2013. 'Islands of Knowledge: Science and Agriculture in the History of Latin America and the Caribbean.' Isis, Vol. 104, No. 4 (December 2013), pp. 788-797 The University of Chicago Press on behalf of The History of Science Society http://www.jstor.org/stable/10.1086/674945 Accessed: 21-10-2017
Rogers, E. M., 1995. 'Diffusion of Innovations.' $4^{\text {th }}$ ed. New York: Free Press.

Rogers, E. M., 1983. 'Diffusion of Innovations'. $3^{\text {rd }}$ ed. London: Collier Macmillan.

Roncaglia, S., 2013. 'Conclusions: Tastes and Cultures.' in 'Feeding the City: Work and Food Culture of the Mumbai Dabbawalas.' Open Book Publishers. Cambridge, UK http://www.jstor.org/stable/j.ctt5vjtm6.9 Accessed 21/10/2017

Song, L., Fang, C and Johnston, L., 2017. 'China's Path Towards New Growth: Drivers of Human Capital, Innovation and Technological Change.' Song, L., Garnaut, R., Fang, C. \& L. Johnston. (eds) 'China's New Sources of Economic Growth: Human Capital, Innovation and Technological Change.' Australian National University Press. Moorebank, Australia http://www.jstor.org/stable/j.ctt1trkk3v.8 Accessed 21/10/2017

Sumberg, J. E and Okali, C., 1997. 'Farmer's Experiments: Creating Local Knowledge'. Boulder: Lynne Rienner.

Tripp, R., Wijeratne, M and Piyadasa, H. V., 2005. 'What Should we Expect from Farmer Field School? A Sri Lanka Case Study'. World Development, 33, (10): 1705-1720.

Whitfield, L., 2005. 'Trustees of Development from Conditionality to Governance: Poverty Reduction Strategy Papers in Ghana'. The Journal of African Studies, 43, (4): 641664.

Wu, Y., Guo, X and Marinova, D., 2017. 'Productivity, Innovation and China's Economic Growth.' Song, L., Garnaut, R., Fang, C. \& L. Johnston. (eds) 'China's New Sources of Economic Growth: Human Capital, Innovation and Technological Change.' Australian National University Press. Moorebank, Australia. http://www.jstor.org/stable/i.ctt1trkk3v.16 Accessed 21/10/2017

Yates, B. L., 2001. 'Applying Diffusion Theory: Adoption of Media Literacy Programs in Schools'. http://www.westga.edu/ byates/a pplying.htm Accessed 20/01/2009. 